\title{
Initial evaluation of psychometric properties of a structured work task application for the Assessment of Work Performance in a constructed environment
}

Elin Karlsson, Gunilla Liedberg and J an Sandqvist

The self-archived postprint version of this journal article is available at Linköping University Institutional Repository (DiVA):

http:/ / urn.kb.se/ resolve?urn=urn:nbn:se:liu:diva-141984

N.B.: When citing this work, cite the original publication.

This is an electronic version of an article published in:

Karlsson, E., Liedberg, G., Sandqvist, J ., (2017), Initial evaluation of psychometric properties of a structured work task application for the Assessment of Work Performance in a constructed environment, Disability and Rehabilitation. https:// doi.org/ 10.1080/09638288.2017.1342279

Original publication available at:

https:/ / doi.org/ 10.1080/09638288.2017.1342279

Copyright: Taylor \& Francis (STM, Behavioural Science and Public Health Titles) http:// www.tandf.co.uk/journals/ default.asp 
Number of words: 6302

Initial evaluation of psychometric properties of a structured work task application for the Assessment of Work Performance in a constructed environment

Elin A. Karlsson ${ }^{1}$, Gunilla M. Liedberg ${ }^{2}$, Jan L. Sandqvist ${ }^{2}$.

1. Department of Medical and Health Sciences, Linköping University, Linköping, Sweden.

2. Department of Social and Welfare Studies, Linköping University, Norrköping, Sweden.

Correspondence to: Elin Karlsson

Department of Medical and Health Sciences, Linköping University,

58183 Linköping, Sweden.

Tel: $+46(0) 737143355$.

E-mail: elin.angelica.karlsson@gmail.com 


\section{ABSTRACT}

PURPOSE: The Swedish Social Insurance Administration has developed a new assessment tool for sickness insurance. This study is a part of the initial evaluation of the application, called the Assessment of Work Performance, Structured Activities, and focuses on evaluation of the psychometric properties of social validity, content validity and utility.

MATERIALS AND METHODS: This was a qualitative study using semi-structured telephone interviews with occupational therapists. A convenience sample was used and participants who fulfilled inclusion criteria $(\mathrm{n}=15)$ were interviewed. Data was analyzed using content analysis with a directed approach.

RESULTS: The results indicate that the application provides valuable information and that it is socially valid. Assessors found work tasks suitable for a diverse group of clients and reported that clients accepted the assessments. Improvements were suggested, for example expanding the application with more work tasks.

The instrument has benefits, however, further development is desired. The use of a constructed environment in assessments may be a necessary option to supplement a real environment. But depending on organizational factors such as time and other resources the participants had different opportunities to do so. Further evaluations regarding ecological validity are essential to ensure that assessments are fair and realistic when using constructed environments.

Keywords: Occupational therapy, vocational rehabilitation, Return to Work, Model of Human Occupation, instrument development. 


\section{INTRODUCTION}

Sickness absence has become a growing public health challenge in Western societies over the last few decades [1-3]. The economic burden of sickness absence is considerable in many countries, and it is a major concern for the authorities to try to reduce these costs. Furthermore, sickness benefit policies are important factors in explaining underlying causes and patterns of sickness absence. Such factors as the design of employment protection, sick leave compensation systems, and the transition from this system to other welfare systems do have an impact on sickness absence levels [4]. One strategy to reduce sickness absence is to provide wellcoordinated interventions in vocational rehabilitation, which generate economic gains for society [5] as well as positive health-related effects for the individual [6]. An important component of the vocational rehabilitation process is the assessment of the clients' work ability. This is necessary to decide upon eligibility for sickness benefits or to establish the clients' need for various vocational rehabilitation interventions [7-8]. Assessment of work ability can be performed in various assessment contexts. It can focus on measuring workers' physical abilities and/or work capacity in simulated assessment environments, but can also involve assessing clients' actual work performance in real work contexts [9].

In Sweden, there are a number of stakeholders involved in the process of assessment of work ability and vocational rehabilitation, where the Swedish Social Insurance Administration (SSIA) is one of the most significant actors [10-11]. One of the SSIA's tasks is to motivate and encourage individuals with sickness benefits to participate in rehabilitation. Together with the individual, the need for rehabilitation must be investigated and planned carefully [12]. The SSIA is not expected to take social and contextual factors into account when assessing work ability. It focuses more on a medical assessment of the individual's prerequisites for work. The SSIA has recently developed and implemented a new national tool for assessment of an individual's capacity for work, called the investigation of activity capacity. The new assessment tool has the purpose of creating a secure and equivalent process in assessing work ability within the sickness insurance system, and to increase participation in assessments and transparency of decisions for those being assessed [12]. The tool is intended to be used primarily by the SSIA in situations when they want to determine whether a sicklisted individual is able to perform work tasks in jobs that normally occur in the labour market. The investigation of activity capacity offers possibilities for a multi-professional assessment of the individual's 
capacity, where one of the professions that can be involved in the assessment process is the occupational therapist [7].

Few assessment instruments assess actual work performance, but rather focus on the assessment of physical abilities or work capacity. One of the first performance-based assessment instruments that focuses on assessment of clients' work ability in meaningful and real work tasks that can provide a foundation for planning occupation-based interventions, is the instrument Assessment of Work Performance (AWP) [9]. The AWP has been chosen as the national assessment instrument to be used by occupational therapists in the investigation of activity capacity [7]. AWP is an observation assessment instrument that measures an individual's work performance. Its aim is to assess a client's skills when performing a specific work task. However, it has been recommended that the AWP be complemented with an array of structured or standardized work tasks to generate linear measures of work performance to enable clinicians and researchers to validly compare scores and/or measures between assessment sessions and/or different clients [9]. Hence, for use within the process of the investigation of activity capacity, a specific application of the instrument has been created called the AWP$\mathrm{SA}^{1}$. This application contains three structured work tasks that offer a simulated work environment for assessment: 1) A sorting and distribution task; 2) An assembly task, and 3) An administrative task.

In order to assess clients' work ability, scientifically developed methods and instruments must be used and continuously evaluated [12]. A correct assessment of work ability with thoroughly tested instruments is essential for making therapeutic decisions based on valid and reliable information [13-14] and may be of importance for clients to acquire the right interventions and rehabilitation [12]. Continuously investigating psychometric properties such as validity, utility and reliability is an essential aspect of developing assessment instruments. Validity has been found to be the most important psychometric property to evaluate for instruments in the area of vocational rehabilitation $[13,15]$. Validity is the degree to which an instrument measures what it is intended to measure $[13,16]$ and content validity is the degree to which test items represent the performance domain the test is intended to measure [13]. Content validity is usually established by a panel of experts who examine the relationship between the purpose of the instrument and its content - the assessment items [17-18]. Content validity is not usually indicated by a statistical measure; rather it is inferred from judgements from experts [19],

\footnotetext{
${ }^{1}$ In Sweden the AWP-SA is called the AWP-FK, named after the SSIA, in Swedish called Försäkringskassan but in the short form, FK.
} 
for example using interviews with the selected experts [20]. The utility of an instrument refers to whether the procedure meets the needs of the assessor and client, and represents the overall value, including relevance, usefulness, efficacy, practicality, ease of administration, and flexibility [21]. To facilitate and promote assessment and treatment, assessments need to be acceptable and socially appropriate to those included. Clients' acceptance and understanding of the assessment they take part in are of great importance [22]. Social validity has its roots in behavioral analysis and includes social importance and acceptability. Social importance refers to whether the client experiences an important improvement or not, and is therefore mainly related to the outcomes of treatment. This study focused mainly on acceptability which is generally assessed solely when focusing on treatment procedures. Acceptability refers to whether an assessment or intervention is appropriate or not, including the clients`view, as well as assessors or the community [23-24].

The psychometric properties of the application AWP-SA have not previously been evaluated. This study is a part of the initial evaluation of the application AWP-SA and focuses on evaluation of the psychometric properties social validity, content validity and utility.

\section{MATERIALS AND METHODS}

\section{Instrument}

AWP is an observation assessment instrument that measures an individual's work performance. Its theoretical foundation is the Model of Human Occupation, and the instrument consists of 14 observational skills in motor skills, process skills and communication and interaction skills [Table 1]. Motor skills are observable actions used to move oneself or to move or handle objects in the work situation. Process skills are observable actions used to plan, modify, and manage the performance of a work task. Communication and interaction skills are performance abilities for dealing with people and for receiving and sharing information. It is not bound to a specific diagnosis, illness or injury and can therefore be used for clients with any kind of work-related problems [25].

(Insert table 1 about here) 
Construct validity, content validity, face validity, internal consistency reliability and utility have previously been tested for the AWP [26-29].

The AWP-SA application contains three structured work tasks that offer a simulated work environment for assessment: 1) A sorting and distribution task; 2) An assembly task, and 3) An administrative task. The SSIA have decided that 120 minutes is the maximum amount of time the assessor has to assess a client, although the assessor has the opportunity to combine tasks the way he or she finds appropriate. The Sorting and distribution task involves sorting mail in post-office boxes. The Assembly task can be performed by either one or two clients and involves assembling shelves and then placing different types of material on them, such as books which are to be sorted in alphabetical order. The Administrative task contains registration of nameplate orders in the Excel program. In all of these work tasks communication between client-assessor can be added to assess communication and interaction skills. The three work tasks have been analyzed with the work task analysis Assessment of Work Characteristics [30] to establish the demands on specific working skills when performing the work task [31].

\section{Study procedures}

An inquiry to test the new application AWP-SA was sent in April 2012 by e-mail to occupational therapists using the AWP. Those who agreed to participate $(\mathrm{n}=71)$ were provided with instructions and the application. Ethical considerations according to guidelines by the Helsinki Declaration [32] have been taken into account, such as written consent, voluntary participation and confidentiality of the material. After four months they were contacted by e-mail to chart who had used the AWP-SA. Inclusion criteria for participation in this study were being an occupational therapist working in Sweden, having completed a three-day course in the AWP, and having used the AWP-SA. A convenience sample was conducted which included all available participants that had the opportunity to participate and that met the inclusion criteria.

\section{Participants}

(Insert table 2 about here) 
In total, 15 participants fulfilled the inclusion criteria and were included in the study. They were situated in different parts of Sweden, they were all female and had used the base instrument AWP, although the application AWP-SA was new to them [table 2]. Reasons for not participating in this study was mainly organizational factors, such as the manager not supporting participation, the application still being new and not fully on stream and lack of time. Further, the time required to set up the assessment environment was an additional excuse. The participants had used the AWP-SA in diverse extent [table 3].

(Insert table 3 about here)

\section{Data collection}

A telephone interview, with a semi-structured interview guide was undertaken in October and November 2012. The participants were located at their work place when the interviews were conducted. The interview guide with open-ended questions had been outlined to ensure that certain areas were discussed during the interview. The questions were inspired by the Assessment Evaluation Inventory [22] and addressed social validity [24], as well as variables for content validity [28] and utility [30] by focusing on the work tasks' suitability in assessing the medical prerequisites for work; whether the work tasks overlapped and/or complemented to each other, and whether the work tasks were appropriate for different clients regarding for instance age, the consequences of their diagnosis and sex. The formulation of the questions and when they were posed during the interview varied, depending on how the conversation developed. The interview guide was piloted over the telephone by the first author prior to the interviews to improve question clarity. This interview [Participant 1] was included in the study. Each interview was audiotaped and varied in length from 30 to 70 minutes. All interviews were conducted, transcribed verbatim, and checked against the tape by the first author.

\section{Data analysis}

A qualitative content analysis with a directed approach was performed on the interview text [33] using the predetermined structure of three stipulated definitions.

1) Utility in this study includes the instrument's equitableness in preparation, ease of administration, and flexibility regarding practical aspects but also diversity among clients being assessed. 
2) Content validity in this study includes the instrument's ability to cover aspects of work ability, that is both the 14 skills and the three work tasks.

3) Social validity in this study includes acceptability of the work tasks for assessors and clients.

All authors read, analyzed, and discussed the material to increase its reliability and trustworthiness. First, each interview was read several times to form a general impression. Second, the text was divided into meaning units, consisting of a sentence, several sentences, or a paragraph with similar meanings. The meaning units were condensed, and collected in the predetermined categories, i.e. the stipulated definitions. Finally, the internal consistency and external plausibility of the category system was tested for its completeness by ensuring that the text content was only recovered in one category (34). Direct quotes from the participants are used in the text to allow one to evaluate the results; they were adapted in written language according to Kvale (35) to avoid stigmatization. In the Results section, brackets [ ] are used to indicate implied words.

\section{RESULTS}

\section{Social validity}

\section{Assessment in real or constructed environment}

The participants reported that real work environments are the optimal alternative when assessing work performance. They also stated that real environments provide a wider picture of the client whereas assessments in constructed environments provide a snapshot of a certain moment in a certain work task. However, they also stated that it was preferable to combine these two contexts and that constructed environments are beneficial if a client lacks insight into his or her limitations. One of the advantages of assessments in constructed environments was stated to be the opportunity for clients to approach work tasks in a more gentle way without letting a potential failure affect production or relations with co-workers and/or the employer.

"You cannot try [a work task] and do it wrong without damaging something. In a constructed environment, it's not real. Because if you make a mistake... it will not affect production or other people” [Participant 5, pain rehabilitation]. 
Another advantage when assessing clients in a constructed environment was described as a chance to map what kind of work would be appropriate for the client if there was no current job to return to. One of the participants highlighted the virtue of assessments in constructed environments if a client has poor relations to co-workers and employers.

"I've assessed a person who... where there are conflicts with the employer in her work place. I believe assessing her in a constructed environment has been considerably better than in her real environment, since there are so many other factors affecting work, which has really nothing to do with her difficulties. There are other things that make her work situation not work" [Participant 10, neurologic rehabilitation].

\section{Appropriate work tasks}

The participants stated that the work tasks were appropriate and that some clients had expressed their appreciation of being assessed in what they believed to be actual work tasks. They also reported that clients seemed interested in receiving an assessment that verified their difficulties while performing a work task.

“The clients I've assessed have not found the work tasks inappropriate. I guess that's the good thing with these work tasks, they are all things you can actually do in working life. So they [the clients] easily see why I'm assessing them in these activities..." [Participant 10, neurologic rehabilitation].

However, another opinion emerged; that the work tasks could be inappropriate if the skills required for the task were very low in comparison to the client's abilities, or if clients overestimated their skills.

"If you've had a very qualified job, sorting mail can be experienced as insulting, even though my assessment may be that the client will have a hard time [managing the work task]... It can be an insight process... And that can provide information to the patient...” [Participant 12, neurologic rehabilitation].

\section{Content validity}

The participants stated that all 14 skills were assessable in the AWP-SA. But that communication and interaction skills were more difficult to observe when clients performed a work task alone; instead, patients' 
interaction with the assessor was included in the assessment. The Administrative task was reported as a challenging task regarding process skills but also as a monotonous task which some clients stated was boring although participants stated it provided information regarding physical and mental endurance. The Assembly task was reported by the participants as the heaviest task regarding motor skills, but they also highlighted reading skills as required for the sorting of books in alphabetical order as challenging for some clients. They stated that the Sorting and distribution task required some level of skill in communication and interaction, as well as motor skills but was the least challenging task since it did not require as much physical or mental endurance as the other two work tasks.

"Mail sorting [Sorting and distribution task] is very simple... I noticed that clients with poor balance or mobility issues, or those with severe attention difficulties found sorting too hard" [Participant 8, pain rehabilitation].

Participants reported that the three work tasks complemented each other since the Sorting and distribution task were performed standing up, the Administrative task sitting down and the Assembly task was been more of a task that required mobility. They stated that there could be some overlap because sorting was part of two work tasks. It was found in the Assembly task, by sorting books in alphabetical order, and in the Sorting and distribution task by sorting mail. However, the participants reported that the Assembly task was the most comprehensive work task.

"The shelves [Assembly task] it provides a comprehensive assessment. You must organize work, be able to carry, remember things, remember where the shelves are supposed to fit, what goes where" [Participant 13, psychiatric care].

To properly assess clients' work performance it was considered that information must be gathered on several occasions. Participants stated this was necessary since clients could have a bad day, for example by being very tired, that might affect the assessment. Of the three work tasks in the AWP-SA, the Assembly task and the Administrative task were considered the most preferable to combine since they provided different information regarding the client's abilities. They reported that a one-hour assessment could provide guidance in assessments 
but did not demonstrate how clients perform over time, which they considered was an issue of importance to ensure correct assessment results.

"Often time is the issue, that they can manage tasks but not over time... The optimal assessment would be over time, longer time. That's how I think it should be” [Participant 1, pain rehabilitation].

The participants also stated that having more work tasks to choose from in the AWP-SA was desirable to ensure suitable work tasks could be found for their clients. They highlighted today's variety in the labor market as one reason for requiring a battery of different work tasks. In order to receive an adequate assessment, participants described the AWP-SA as part of a total rating where assessments in real environments as well as from other team members could be included.

\section{Utility}

In general, assessment environments were found possible to set up by the participants and costs were low or absent. Furthermore, material for the work tasks was often available in the work place. However, they stated that the Assembly task required more resources from the work place regarding space and material. Four participants were not able to set up this work task. The participants also reported that the Administrative task was the easiest one to set up since it required a small quantity of material. Furthermore, they found it time-consuming to prepare the Sorting and distribution task by writing addresses on the letters included in this task. Completion time when assessing clients varied from 10 (Sorting and distribution task) to 90 (Assembly task) minutes. Depending on their clients difficulties the participants could use two or all three of the tasks within the SSIAs time limit of 120 minutes. They stated that the manual in the AWP-SA provided sufficient guidance to conduct assessments but preferred extra information to be given in some parts of the manual. For example, they requested guidelines for the Assembly task regarding the weight of material that clients should place on shelves. Participants stated that detailed guidelines could result in a fairer assessment.

"If I fill the binders with loads of paper and use really heavy books... and then I do an assessment. And later on someone else does an assessment of the client somewhere else perhaps just using some paper and empty binders" [Participant 4, pain rehabilitation]. 
However, participants also preferred a certain amount of flexibility, for example participants said they wanted to be able to add distractions such as turning the radio on and leaving the door or a window open. This allowed them to adapt, whichever work task in the AWP-SA they chose, to a specific client, depending on how high or low they wanted the demands of the work task to be.

“You may have a person previously employed as a lumberjack to assess, who isn't used to computer work. Then maybe you shouldn't choose that work task. The other two are more practical, which is good to have... practical alternatives"[Participant 11, psychiatric care].

Participants also highlighted that the AWP-SA could complement the Assessment of Motor and Process Skills.

"It has been a limitation just using the Assessment of Motor and Process Skills since it's so focused on household tasks. If you intend to assess work ability these work tasks [in the AWP-SA] are more like actual work tasks" [Participant 5, pain rehabilitation].

It was considered the work tasks could be used for assessing different clients regarding age, ethnicity, function and education. But participants reported that computer skills may affect the assessment in the Administrative task, and communication and interaction skills may affect the assessment in all three work tasks. They reported they had assessed clients with inadequate skills in the Swedish language and that this caused difficulties assessing whether the clients' difficulties in the work task were due to language problems or insufficient attention.

"It's also about communication and interaction skills in this nameplate ordering task [Administrative task] and understanding instructions to sort mail in different bins [Sorting and distribution task]. If you don't understand Swedish these tasks will be difficult for you" [Participant 3, neurologic rehabilitation].

Another situation was reported by one of the participants in the Administrative task where the client had experience of the computer program Excel and knew the functions of this program. This client was frustrated since these functions were not usable in the AWP-SA and instead generated faults when he applied them. The participant in this case stated that the Administrative task was too trivial with respect to the client's knowledge. 


\section{DISCUSSION}

In this study the participants reported that the AWP-SA was usable since it covered different aspects of work ability, for clients with various functions and sociocultural backgrounds and also was easy to administer overall. They stated all 14 skills were assessable although skills in communication and interaction were harder to assess when assessing clients alone. Suggestions for improvement are, for example, to include additional work tasks, some of which should make higher demands concerning communication and interaction so that these skills can more easily be assessed.

In this study, the participants stated that the three work tasks were appropriate and that their clients accepted assessment with the AWP-SA. If work tasks seem acceptable and socially appropriate, social validity exists [22]. However, this study is based on 15 participants with varying experience of the AWP-SA, and thus the study cannot be claimed to represent all current users. To engage a broader population a future study could be performed using quantitative methods. Telephone interviews are considered beneficial to gain geographical spread [36], which was the case in this study where participants represented different parts of Sweden. A disadvantage is the loss of non-verbal communication [36]. The primary strength of a content analysis with a directed approach is that a theory can be confirmed and expanded [33]. In this study, stipulated definitions were used. These stipulated definitions were reviewed by other researchers, in this case the second and third author, which, according to Hsieh and Shannon, [33] is a strength. More studies must be carried out to further evaluate validity and utility. This study, however, indicates that social validity, content validity and utility seem to exist for the AWP-SA although several improvements are desired. The application must continue to be developed, and further studies must be carried out involving more users. In future studies it is also important to include the client's perspective to gain a deeper understanding of the social validity of AWP-SA. Including client's perspectives is meaningful since occupational therapists as well as other professions work in a client-centered manner and examine their clients’ needs. Evaluating social validity in occupational therapy is unusual [24], and this study provides new knowledge by indicating social validity for an occupational therapy assessment instrument in the area of vocational rehabilitation. 
An interesting finding of this study was the consensus amongst participants regarding the strength of assessment in a real environment. Accuracy increases if the assessment of work ability is carried out in a real environment in a work task relevant for the client but a real environment is not always an option. Assessors often have specific directions depending on their commission and finding an optimal assessment situation can be a challenge. Therefore a constructed environment is a necessary option to real environment [29]. In this study, the participants also preferred assessment in a real environment but stated that assessing clients in a constructed environment could be a strength since it provided an opportunity for clients to practice on work tasks in a safer environment, and also prevented poor relations with co-workers and supervisors from affecting the assessment and in the longer term influencing the possibility to remain at work, since relations at work have been shown to affect work ability [37-38].

To evaluate whether an assessment in a constructed environment is fair and similar enough compared to a real environment the assessment instrument's ecological validity must be tested [24], i.e. the assessment environment must be realistic and representative of the phenomena being assessed so that the client's behavior is as natural as possible when being assessed [39]. An assessment instrument that includes the skills, objects and activities required in a real environment would definitely have ecological validity [40]. Further evaluations of ecological validity to ensure just assessments with the AWP-SA are essential. A future study could for example assess clients in the same work task in both a constructed and real environment to evaluate whether these two assessment environments are equivalent or not in a specific work task. Both social validity and ecological validity can contribute to research by facilitating the use of instruments and interventions [24]. By tradition, content validity and utility are tested first, but other forms of validity such as ecological validity and social validity are also important when it comes to ensuring equivalent assessments. Therefore, it is desired that the other alternatives of validity are also tested when evaluating instruments.

\section{LIMITATIONS}

All interviews were conducted and transcribed verbatim by the first author. This is a limitation that may affect this study's reliability. However, two of the authors have been involved in discussions regarding the interviews, such as development of the interview guide, possible follow-up cues when conducting the interviews and 
discussions of appropriate interview technique. To increase this study's trustworthiness all authors have also been involved in the process of analyzing the data.

In this initial evaluation participants were recruited and those who had had the time to actually test the instrument in their work were included for telephone interviews. This may have affected the result if the participation of the participants interviewed depended on them having the right organizational conditions to use the AWP-SA, for example sufficient space for setting up assessment stations. Another potential limitation of the application AWP-SA is the time required to set up the assessment environment, since this was one of the main reasons for not participating in this study. This indicates that the utility of the application is affected negatively because of the time factor. Other reasons for not participating in this study were the supervisor not giving his/her support and the application being new and not fully onstream. The flexibility when setting up assessment stations is a limitation with the application that participants highlight since assessments could be unequal with for example the variety of the weight of the material. However, the flexibility of the application is also highlighted as a strength regarding the opportunity to adapt work tasks to a specific client. The transferability of the results must be regarded as limited, due to the small sample size. The fact that many of the participants did not have experience of all the tasks and that the majority only had experiences of a few assessments is also considered a limitation in this study. For example nine of the participants had no experience of assessments using the assembly task which means further evaluation with a broader population must be performed.

Clients who cannot speak or understand Swedish have not been assessed in any of the tasks in this study, although some had limited communication skills. Participants highlighted the need to know the Swedish language as a limitation in the AWP-SA and stated clients without sufficient communication and interaction skills will have a hard time being assessed in any of the existing work tasks. Therefore work tasks appropriate for this group need to be considered, for example, translating instructions to clients into other languages.

\section{ACKNOWLEDGEMENTS}

We would like to thank the participants for their participation in this study. 


\section{Disclosure of interest}

The authors report no conflicts of interest. 


\section{REFERENCES}

[1]. Gimeno, D., Benavides, F., Benach J., Amick, B. $3^{\text {rd: }}$ Distribution of sickness absence in the European Union countries. Occup Environ Med 2004;61:867-869.

[2]. Organisation For Economic Co-Operation and Development: Sickness, disability and work: Breaking the barriers, Volume 3. Denmark, Finland, Ireland and The Netherlands: Paris: OECD; 2008. [3]. Organisation For Economic Co-Operation and Development: Economic Policy Reforms: Going for growth. Paris: OECD; 2009.

[4]. Krane L, Johnsen R, Fleten N, Vinther Nielsen C, Stapelfeldt C.M, Jensen C, Braaten T. Sickness absence patterns and trends in the health care sector: 5-year monitoring of female municipal employees in the health and care sectors in Norway and Denmark, Human Resources for Health 2014;12:37.

[5]. Kärrholm J,Ekholm K,Jakobsson B,Ekholm J, Bergroth A,Schüldt K. Effects on work resumption of a co-operation project in vocational rehabilitation. Systematic, multi-professional, client-centered and solution-oriented co-operation, Disability and Rehabilitation, 2006;28:7, 457-467.

[6]. Dutta A, Gervey R, Chan F, Chou C-C, Ditchman N. Vocational rehabilitation services and employment outcomes for people with disabilities: A United States study, Journal of Occupational Rehabilitation 2008;18:326-334.

[7]. Leijon O, Hamrén B, Larsson M, Wahlfridsson A, Österlund N. A new model for assessment of an individual’s capacity for work, ISF Report 2015:8, Swedish Social Insurance Inspectorate, Stockholm, 2015. [8]. Ståhl, C, Svensson, T, Petersson, G, Ekberg, K. The work ability divide: Holistic and reductionistic approaches in Swedish interdisciplinary rehabilitation teams, Journal of Occupational Rehabilitation, 2009;19:264-273.

[9]. McFadden, S., MacDonald, A., Fogarty, A., Le, S., Merritt, B. K. Vocational assessment: A review of the literature from an occupation-based perspective. Scandinavian Journal of Occupational Therapy. 2010;17(1):4348.

[10]. Ståhl, C, Svensson, T, Ekberg, K. A matter of trust? A study of coordination of Swedish stakeholders in return-to-work. Journal of Occupational Rehabilitation, 2010;20(3):299-310.

[11]. Seing, I, Ståhl, C, Nordenfelt, L, Bülow, P, Ekberg, K. Policy and practice of work ability: A negotiation of responsibility in organizing return to work, Journal of Occupational Rehabilitation, 2012;22(4):553-564. 
[12]. Swedish Government Official Report, SOU (2010). Arbetslivsinriktad rehabilitering. [Vocational rehabilitation]. SOU 2010:04. [cited 2015 April 15]. Report available at http://www.psfu.se/uploads/files/7_arbetslivsinriktad_rehabilitering.pdf Swedish.

[13]. Kielhofner, G., Forsyth, K. Assessment: Choosing and using structured and unstructured means of gathering information. In: Kielhofner, G. A Model of Human Occupation. Philadelphia: Lippincott, Williams and Wilkins; 2008. pp. 155-70.

[14]. Kjellin, L., Cizinsky Sjödahl, R., Eklund, M. Activity-based assessment (BIA) - inter-rater reliability and staff experiences. Scandinavian Journal of Occupational Therapy. 2008;15:75-81.

[15]. Kielhofner, G. A Model of Human Occupation (MOHO). Philadelphia: Lippincott, Williams and Wilkins; 2008.

[16]. Polit, D.F., Beck, C.T. Nursing research -principles and methods. Philadelphia: J.B. Lippincott Company; 2004.

[17]. Johnston, M. V., Keith, R. A., Hinderer, S. R. Measurement standards for interdisciplinary medical rehabilitation. Archives of Physical Medicine and Rehabilitation.1992;73:3-23.

[18]. Thorn, D. W., Deitz, J. C. Examining content validity through the use of content experts. Occupational Therapy Journal of Research. 1989;9:334-346.

[19]. Dunn, W. Reliability and validity, in: Developing norm-referenced standardised tests, L.J. Miller, Ed., New York: Haworth Press, 1989.

[20]. Haynes, S., Richard, D., Kubany, E. Content Validity in Psychological Assessment: A Functional Approach to Concepts and Methods. Psychological Assessment. 1995;7:3,238-247.

[21]. Innes, E., Straker, L. Attributes of excellence in work-related assessments. Work. 2003;20:63-76.

[22]. Rhule, D., McMahon, R., Vando, J. The acceptability and representativeness of standardized parent-child interaction tasks. Behavior Therapy. 2009;40 393-402.

[23]. Foster, S., Mash, E. Assessing social validity in clinical treatment research - issues and procedures. Journal of consulting and clinical psychology. 1999;67(3):308-319.

[24]. Sudsawad, P. A conceptual framework to increase usability of outcome research for evidence-based practice. American Journal of Occupational Therapy. 2005;59(3):351-55. 
[25]. Sandqvist, J. The Assessment of Work Performance (AWP), Version 2.0. In Swedish. Linköping: Faculty of Health Sciences, Department of Social- and Welfare Studies; 2008.

[26]. Sandqvist, J., Gullberg, M., Henriksson, C., Gerdle, B. Content validity and utility of the Assessment of Work Performance (AWP). Work. 2008;4:441-50.

[27]. Sandqvist, J., Björk, M., Gullberg, M., Henriksson, C., Gerdle, B. Construct validity of the Assessment of Work Performance (AWP). Work. 2009;32(2):211-8.

[28]. Sandqvist, J., Törnqvist, K. \& Henriksson, C. (2006). Assessment of Work Performance - Development of an Instrument. Work, 26, 379-387.

[29]. Fan, C. W., Taylor, R., Ekbladh, E., Hemmingsson, H. \& Sandqvist, J. (2013). Evaluating the psychometric properties of a clinical vocational rehabilitation outcome measurement: The Assessment of Work Performance. OTJR: Occupation, Participation and Health, 33 (3), 125-133.

[30]. Sandqvist J., Development and evaluation of validity and utility of the instrument Assessment of Work Performance (AWP). [dissertation]. Linköping: Linköping university; 2007.

[31]. Sandqvist, J. \& Edström, E. Manual för användning av bedömningsinstrumentet Assessment of Work Performance (AWP) vid arbetsterapeutisk kompletterande undersökning av medicinska förutsättningar för arbete: AWP-SA. [Manual for using the Assessment of Work Performance (AWP) in occupational therapy complementary testing of medical prerequisites for work: AWP-SA]. Linköping: Faculty of Health Sciences, Department of Social- and Welfare Studies; 2011. Swedish.

[32]. World Medical Association. World Medical Association declaration of Helsinki - Ethical principles for research involving human subjects. The Journal of the American Medical Association. 2013;310(20):21912194.

[33].Hsieh, H., Shannon, S. Three approaches to qualitative content analysis. Qualitative health research. 2005;15(9):1277-88.

[34]. Malterud, K. Qualitative research: standards, challenges, and guidelines. Lancet, 2001;358:483-488.

[35]. Kvale, S. Interviews: An introduction to qualitative research interviewing. London: Sage publication Inc; 1996.

[36]. Gilham, B. Forskningsintervjun: tekniker och genomförande. [The research interview: techniques and procedure]. Lund; Studentlitteratur: 2008. Swedish.

[37]. Liedberg, G. M., Björk, M. Symptoms of subordinated importance in fibromyalgia when differentiating working from non-working women. Work. 2014;48:155-164. 
[38]. Sturesson, M., Edlund, C., Fjellman-Wiklund, A-C, Hansen-Falkdal, A., Bernspång, B. Work ability as obscure, complex and unique: Views of Swedish occupational Participants and Physicians. Work. 2013;45:117128.

[39]. Schmuckler, M. What is ecological validity? A dimensional analysis. Infancy. 2001;2(4):419-436.

[40]. Sbordone, R., Long, C. Ecological validity of neuropsychological testing. Orlando: GR Press/St Lucie Press; 1996. 
Table 1. Skills assessed in the AWP-SA.

\begin{tabular}{lll}
\hline Motor skills & Process skills & $\begin{array}{l}\text { Communication and interaction } \\
\text { skills }\end{array}$ \\
\hline Posture & Mental energy & $\begin{array}{l}\text { Physical communication and } \\
\text { interaction }\end{array}$ \\
Mobility & Knowledge & Language \\
Coordination & Temporal organization & Social contacts \\
Strength and handling of objects & Organization of workplace & Information exchange \\
Physical energy & Adaptation & \\
\hline
\end{tabular}

Table 2. Characteristics of the participants.

\begin{tabular}{|c|c|c|c|}
\hline & Age & $\begin{array}{l}\text { Experience in assessing } \\
\text { work ability }\end{array}$ & Primary work area \\
\hline Participant 1 & 39 & 2 years & Pain rehabilitation \\
\hline Participant 2 & 61 & 22 years & Psychiatric care \\
\hline Participant 3 & 48 & 10 years & Neurologic rehabilitation \\
\hline Participant 4 & 59 & 26 years & Pain rehabilitation \\
\hline Participant 5 & 46 & 10 years & Pain rehabilitation \\
\hline Participant 6 & 57 & $1 \frac{1 / 2}{\text { years }}$ & Psychiatric care \\
\hline Participant 7 & 37 & $21 / 2$ years & Pain rehabilitation \\
\hline Participant 8 & 45 & 5 years & Pain rehabilitation \\
\hline Participant 9 & 57 & 22 years & Neurologic rehabilitation \\
\hline Participant 10 & 46 & 9 years & Neurologic rehabilitation \\
\hline Participant 11 & 37 & $21 / 2$ years & Psychiatric care \\
\hline Participant 12 & 56 & 1 years & Neurologic rehabilitation \\
\hline Participant 13 & 48 & 1 years & Psychiatric care \\
\hline Participant 14 & 52 & 8 months & Neurologic rehabilitation \\
\hline Participant 15 & 50 & 4 years & Psychiatric care \\
\hline Mean & 49.2 & 8 years & \\
\hline
\end{tabular}


Table 3. The number of assessments of the participants using the AWP-SA.

\begin{tabular}{|c|c|c|c|}
\hline & Administrative task & Assembly task & $\begin{array}{l}\text { Sorting and distribution } \\
\text { task }\end{array}$ \\
\hline Participant 1 & 2 & 0 & 0 \\
\hline Participant 2 & 50 & 0 & 0 \\
\hline Participant 3 & 4 & 0 & 0 \\
\hline Participant 4 & 8 & 0 & 0 \\
\hline Participant 5 & 5 & 7 & 18 \\
\hline Participant 6 & 2 & 0 & 3 \\
\hline Participant 7 & 2 & 0 & 0 \\
\hline Participant 8 & 10 & 0 & 30 \\
\hline Participant 9 & 1 & 4 & 2 \\
\hline Participant 10 & 3 & 1 & 3 \\
\hline Participant 11 & 2 & 0 & 1 \\
\hline Participant 12 & 0 & 1 & 1 \\
\hline Participant 13 & 2 & 2 & 2 \\
\hline Participant 14 & 3 & 0 & 0 \\
\hline Participant 15 & 3 & 2 & 4 \\
\hline Total & 97 & 17 & 64 \\
\hline
\end{tabular}

